DOI 10.37882/2223-2982.2021.04-2.07

\title{
СРЕДНИЙ ВОЗРАСТ ПОДАТНЫХ КАТЕГОРИЙ КРЕСТЬЯН, ПРОЖИВАЮЩИХ НА ТЕРРИТОРИИ МОРДОВСКОГО КРАЯ ВО ВТОРОЙ ПОЛОВИНЕ ХVIII ВЕКА ПО МАТЕРИАЛАМ КРАСНОСЛОБОДСКОГО УЕЗДА ШАЦКОЙ ПРОВИНЦИИ ВОРОНЕЖСКОЙ ГУБЕРНИИ (ПО НАСЕЛЕННЫМ ПУНКТАМ)
}

\section{AVERAGE AGE OF TAXABLE CATEGORIES OF PEASANTS LIVING ON THE TERRITORY OF THE MORDOVIAN TERRITORY IN THE SECOND HALF OF THE XVIII CENTURY ACCORDING TO THE MATERIALS OF KRASNOSLOBODSKY UYEZD OF THE SHATSKY PROVINCE OF THE VORONEZH PROVINCE (BY LOCALITIES)}

D. Efimkin

Summary: The purpose of the work is to conduct a comparative analysis of the average age dynamics of the taxable population of the Mordovian territory in the second half of the XVIII century in various localities and peasant categories on the example of Krasnoslobodsky uyezd of the Shatsky province of the Voronezh province.

Method. The methodological potential includes: a comparative historical method, the use of which makes it possible to show a comparative analysis of the development of various families and localities; a statistical method, the significance of which is obvious for analyzing data related to changes in the peasant family over the period under study.

Result. The study showed the following results.

1) At the beginning of the second half of the XVIII century on the territory of the modern Republic of Mordovia, the average life expectancy was 26.24 years.

2) In most cases, the population of these places belonged to the category of palace peasants, but there were also landowner peasants, household people, soldiers and odnodvortsy.

3) The highest average age was among 2 categories: artisans-28.23 years and palace peasants- 26.92 years. The runaway palace peasants had the smallest average age -14.15 years.

4) During the comparative analysis of the Moscow and Voronezh provinces, significant differences were revealed, since the life expectancy in the Moscow province was significantly higher.

Conclusions. In general, the data obtained showed that the life expectancy on the territory of the Mordovian Territory in the second half of the XVIII century remained at a low level. It can also be assumed that the situation of artisans and palace peasants was much better than that of the rest of the tax-paying population.

Keywords: peasant family, age, average age, life expectancy, taxable population.
Ефимкин Денис Геннадьевич

Аспирант, НИИ Гуманитарных наук при правительстве РМ, г. Саранск

efimkin.denis@mail.ru

Аннотация: Цель работы - провести сравнительный анализ средневозрастной динамики податного населения Мордовского края во второй половине XVIII века в различных населенных пунктах и крестьянских категориях на примере Краснослободского уезда Шацкой провинции Воронежской губернии.

Метод. Методологический потенциал включает: сравнительно исторический метод, применение которого позволяет показать сравнительный анализ развития различных семей и населенных пунктов; статистический метод, значимость которого очевидна для анализа данных, связанных изменениями в крестьянской семье на протяжение исследуемого периода.

Результат. Исследование показало следующие результаты.

1) В начале второй половины XVIII века на территории современной Республики Мордовия средняя продолжительность жизни составила - 26,24 года. 2) В большинстве случаев население данных мест относились к категории дворцовые крестьяне, но были и помещичьи крестьяне, дворовые люди, солдаты и однодворцы.

3) Самый большой средний возраст был среди 2-х категорий: мастеровые люди - 28,23 года и дворцовые крестьяне - 26,92 года. Самый маленький средний возраст был среди беглых дворцовых крестьян - 14,15 года.

4) В ходе проведения сравнительного анализа Московской и Воронежских губерниях выявляются существенные отличия, так как продолжительность жизни в Московской губернии была существенно выше.

Выводы. В целом полученные данные показали, что на продолжительность жизни на территории Мордовского края во второй половине XVIII века оставалась на низком уровне. Также можно предположить, что положение мастеровых людей и дворцовых крестьян было намного лучше, чем у остального податного населения.

Ключевые слова: крестьянская семья, возраст, средний возраст, продолжительность жизни, податное население. 
B предыдущей статье был поднят вопрос о среднем возрасте крестьянского населения, которое проживало на территории Мордовского края во второй половине XVIII века. В ней была рассмотрена общая повозрастная структура мужского населения, средний возраст детского и взрослого населения.

В данной статье будет продолжено рассмотрение материалов II ревизии, а именно среднего возраста податного населения в различных населенных пунктах и крестьянских категориях.

Процесс рассмотрения стоит начать с того, что по итогам II ревизии в уезде числилось 4944 души, которые относились к 2844 семьям. Подробный анализ характеристики продолжительности жизни в различных населенных пунктах Краснослободского уезда можно увидеть в гистограмме 1.

Всего было приведено 35 населенных пунктов:

1. Так в г. Красная слобода разночинцев, дворовых людей, дворовых бобылей и однодворцев- 113 душ. Средний возраст составил - 22,52 года.

2. Дворцовых крестьян в Поташной слободе насчи- тывалось - 38 душ. Средний возраст составил 26,33 года.

3. В Панших слободах дворцовых крестьян насчитывалось 34 души. Средний возраст составил - 17,34 года.

4. В Сотне Погорной дворцовых крестьян, крестьян и беглых крестьян насчиталось - 353 души. Средний возраст составил - 23,71 года.

5. В Заречной сотни дворцовых крестьян составило 228 душ. Средний возраст - 25,72 года.

6. В Сотни Логинова дворцовых крестьян - 337 душ. Средний возраст составил - 25,53 года.

7. Дворцовых крестьян в сотни татарской - 197 душ. Средний возраст составил - 26,52 года.

8. В Пушкаревской слободе однодворцев - 29 душ. Средний возраст - 29 лет.

9. В Солдатской пятине однодворцев, старых служивых солдат составило - 162 души. Средний возраст - 23,05 года.

10. В деревне Полянки дворцовых крестьян - 40 душ. Средний возраст - 26,8 года.

11. В селе Новодемьяновское однодворцев - 48 душ. Средний возраст составил - 27,68 года.

12. В селе Шаверки дворцовых крестьян - 279 душ.

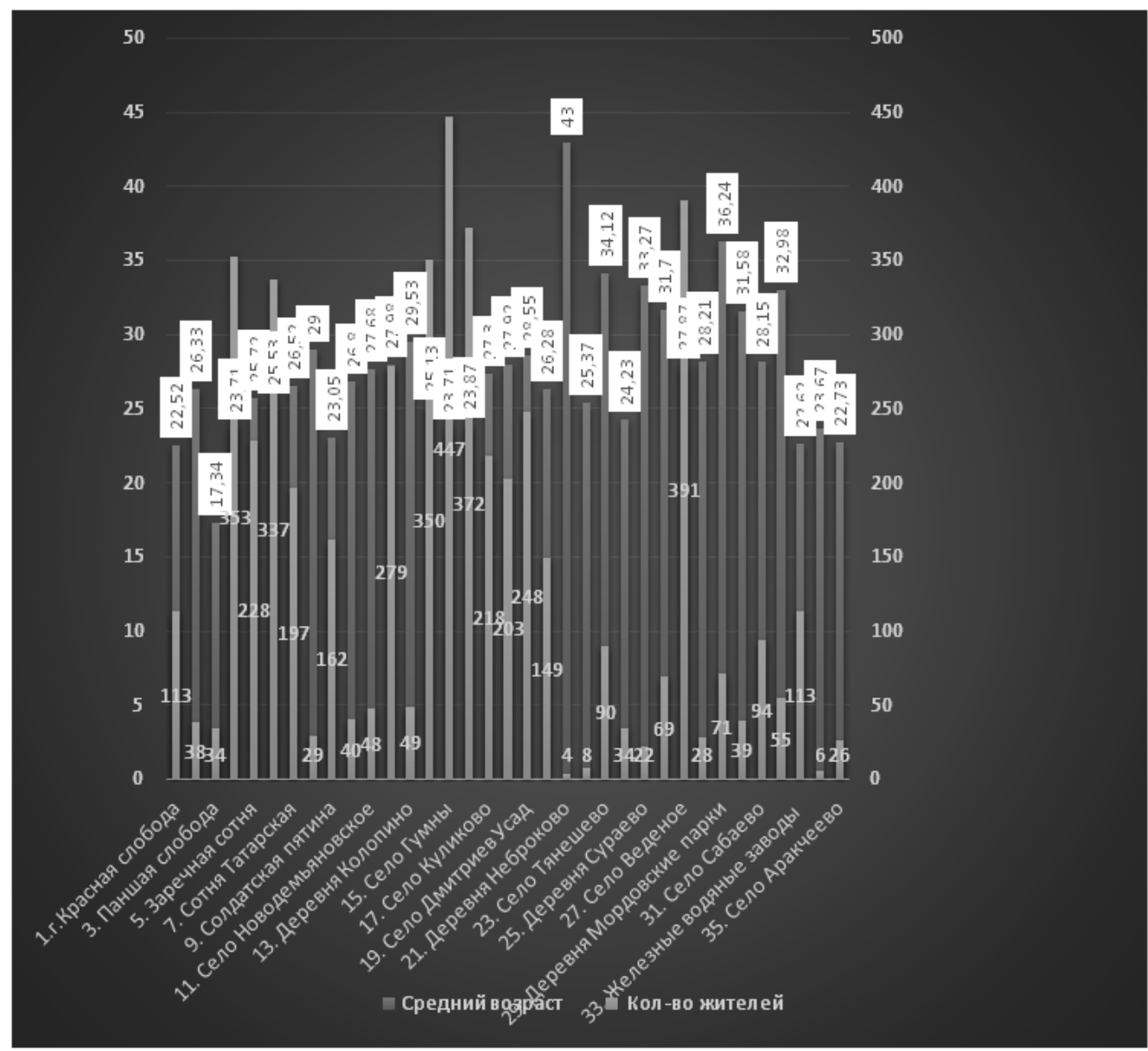

Гистограмма 1. Средний возраст и количество жителей г. Красная слобода и Краснослободского уезда за 1745 г (по населенным пунктам) 
Средний возраст - 27,98 года.

13. В деревне Колопино дворцовых крестьян - 49 душ. Средний возраст - 29,53 года.

14. В селе Дубровы однодворцев и дворцовых крестьян - 350 душ. Средний возраст 25,13 года.

15. В селе Гумны дворцовых крестьян - 447 душ. Средний возраст составил - 23,71 года.

16. В селе Плужное дворцовых крестьян - 372 души. Средний возраст - 23,87 года.

17. В селе Куликово дворцовых крестьян - 218 душ. Средний возраст 27,3 года.

18. В селе Ефаево дворцовых крестьяне - 203 души. Средний возраст - 27,92 года.

19. В селе Дмитриев Усад дворцовых крестьян - 248 душ. Средний возраст - 28,55 года.

20. В селе Новый Усад дворцовых крестьян - 149 душ. Средний возраст - 26,28 года.

21. В деревне Неброково дворцовых крестьян - 4 души. Средний возраст - 43 года.

22. В деревни Кулясь дворцовых крестьян - 8 душ. Средний возраст - 25,37 года.

23. В селе Тянешево дворцовых крестьян - 90 душ. Средний возраст - 34,12 года.

24. В деревни Лаушки дворцовых крестьян - 34 души. Средний возраст - 24,23 года.

25. В деревни Сураева починки дворцовых крестьян 22 души. Средний возраст - 33,27 года.

26. В селе Ишаево дворцовых крестьян - 69 душ. Средний возраст - 31,7 года.

27. В селе Веденое дворцовых крестьян - 391 душа. Средний возраст - 27,87 года.

28. В деревне Долговерясы дворцовых крестьян - 28 душ. Средний возраст - 28,21 года.

29. В деревне Мордовские парки дворцовых крестьян - 71 душа. Средний возраст - 36,24 года.

30. В деревне Зубарево дворцовых крестьян - 39 душ. Средний возраст - 31,58 года.

31. В селе Сабаево дворцовых крестьян - 94 души. Средний возраст - 28,15 года.

32. В деревни Дергуново дворцовых крестьян - 55 душ. Средний возраст - 32,98 года.

33. В железных водяных заводах дворовых и мастеровых людей составило - 113 душ. Средний возраст - 22,62 года.

34. В Темниковском винокуренном заводе дворовых людей - 6 душ. Средний возраст - 23,67 года.

35. В селе Аракчеево дворцовых крестьян - 26 душ. Средний возраст - 22,73 года.

Как мы видим средний возраст населения в разных населенных пунктах почти не отличался друг от друга и в большинстве случаев соответствовал среднему возрасту по Уезду. Исключениями стали несколько населенных пунктов таких как: Паншие слободы - 17,34 года, деревня Неброково - 43 года, село Тянешево - 34,12 года, деревня Сураева Починки - 33,27 года, деревня Мордов- ские парки - 36,24 года.

В большинстве случаев население данных мест составляют дворцовые крестьяне, но были и помещичьи крестьяне, дворовые люди, солдаты и однодворцы

В некоторых населенных пунктах проживало несколько категорий крестьян. Так, например, в г. Красная слобода проживали помещичьи крестьяне и дворовые люди; в Заречной сотне проживали дворцовые крестьяне, некрещенные и мордва; в селе Куликово проживали ясачные и дворцовые крестьяне; церковные и дворцовые крестьяне проживали в селе Дмитриев Усад; в селе Веденное проживали однодворцы и дворцовые крестьяне.

К сожалению, в связи с тем, что материалов по российской демографии до начала второй половины XIX века недостаточно. Поэтому для сравнения была использована работа Троицкой И.А. и французского демографа Блюма А., которая посвящена вопрос продолжительности жизни в России в XVIII веке [2]. К сожалению, работа освящает лишь территорию Московской губернии, однако она уже ценна тем, что позволяет провести сравнительный анализ, а также проливает свет на продолжительность жизни населения России в тот период.

Основываясь на данных ревизских сказок и метрических книг, Троицкая и Блюм оценили уровень смертности для Московской губернии в 1745-1763 и в 1851-1858 годах и на основе этих оценок рассчитали продолжительность жизни в разных возрастах (рис.1.1.). Показатели для возрастов моложе 10-20 лет менее точны, чем для более старших, из-за недостаточной регистрации детей.

Если расчёты Троицкой и Блюма верны, то получается, что продолжительность жизни в середини XVIII века при рождении составляли 24-25 лет, но если человек переживал раннее детство, то в возрасте 10 лет ему предстояло жить в среднем ещё 41 год (51 год в общей сложности), а дожившему до 20 лет ещё 33-34 года (53-54 года в общей сложности).

Таким образом, при сравнении данных, полученных в Московской и Воронежских губерниях, выявляются существенные отличия, так как продолжительность жизни в Московской губернии была существенна выше.

Далее стоит рассмотреть влияла отношение крестьян к той или иной категории на продолжительность жизни населения. Детальное описание категорий, количества населенных пунктов в которых они представлены, число умерших жителей, а также средняя продолжительность жизни представлены в таблице 1 и гистограмме 2. Всего было представлено 10 категорий крестьян: 
TABLEAU 5. - ESPÉRANCE DE VIF À DIVERS ÂGFS

RÉGION DE MOSCOU (1745-1763 ET 1851-1858; ISTIMATION À PARTIR DFS REVISIONS). ET TABLFS RUSSES ESTIMF́ESS AU XIX ${ }^{\mathrm{c}}$ SIËCLE

\begin{tabular}{|c|c|c|c|c|c|c|c|}
\hline \multirow{2}{*}{$\hat{\mathrm{Age}}$} & \multicolumn{3}{|c|}{ Région de Moscou } & \multirow{2}{*}{\begin{tabular}{|c|} 
Andreev \\
$1851-1860$
\end{tabular}} & \multirow{2}{*}{$\frac{\text { Bunjakovskij }}{1862}$} & \multirow{2}{*}{\begin{tabular}{|l|} 
Bortkevic \\
$1874-1883$
\end{tabular}} & \multirow{2}{*}{$\begin{array}{c}\begin{array}{c}\text { Besser et } \\
\text { Ballod }\end{array} \\
1867-1890\end{array}$} \\
\hline & $1745-1763$ & $\begin{array}{c}1745-1763 \\
\text { corrigé }\end{array}$ & $1851-1858$ & & & & \\
\hline $\operatorname{lgO}$ & (49) & 334 & 334 & 284 & 265 & 327 & 300 \\
\hline 0 & $(38.4)$ & 24.2 & 24.4 & 25.5 & 30.9 & 26.4 & 27.2 \\
\hline 1 & $(39,3)$ & 35,5 & 35.5 & 34.5 & 40.8 & 37.9 & 37.8 \\
\hline 5 & $(41,6)$ & 42,8 & 42,9 & 39.3 & 46,2 & 45.8 & 44.2 \\
\hline 10 & 41,0 & 41,2 & 41,4 & 37.4 & 44,2 & 44,6 & 43.2 \\
\hline 20 & 34,2 & 33,9 & 34,4 & 30,5 & 36,9 & 37,4 & 36.7 \\
\hline 30 & 27,5 & 27,2 & 27,1 & 24,7 & 30,1 & 30,4 & 30,1 \\
\hline 40 & 21,0 & 20,7 & 20,5 & 19,2 & 23,6 & 23,4 & 23,5 \\
\hline 50 & 15,7 & 15,5 & 14,5 & 14,9 & 17,9 & 17,1 & 17.5 \\
\hline 60 & 11,0 & 10,6 & 8,9 & 12,2 & 12,3 & 11,6 & 12.2 \\
\hline
\end{tabular}

Рис. 1.1. Младенческая смертность ожидаемая продолжительность жизни в разных возрастах Московская область (1745-1763 и 1851-1858 гг.)

Таблица 1.

Средний возраст по категориям крестьян в г. Красная слобода и Краснослободского уезда за 1745 г.

\begin{tabular}{|l|l|c|c|c|}
\hline \multicolumn{1}{|c|}{ Категория крестьян } & Кол-во населенных пунктов & Кол-во жителей & Средняя возраст \\
\hline & Разночинцы & 1 & 5 & 24,6 \\
\hline & Дворовые люди & 3 & 116 & 21,5 \\
\hline & Дворовые бобыли & 1 & 74 & 26,87 \\
\hline & Однодворцы & 5 & 599 & 24,4 \\
\hline & Дворцовые крестьяне & 27 & 3824 & 26,92 \\
\hline & Крестьяне & 1 & 18 & 24,9 \\
\hline & Беглые дворцовые крестьяне & 1 & 84 & 14,15 \\
\hline & Татары & 1 & 197 & 26,52 \\
\hline 0 & Старые служивые солдаты & 1 & 14 & 25,36 \\
\hline
\end{tabular}

1. Разночинцы были представлены в 1-м населенном пункте, общей численностью 5 душ. Средний возраст составил - 24,6 года;

2. Дворовые люди были представлены в 3-х населенных пунктах, общей численностью 116 душ. Средний возраст составил - 21,5 года;

3. Дворовые бобыли числились в 1-м населенном пункте, общей численностью 74 души. Средний возраст составил - 26,87 года;

4. В 5-и населенных пунктах числились однодворцы, общая численность которых составила 599 душ. Средний возраст составил - 24,4 года;

5. Дворцовые крестьяне были представлены в 27-и населенных пунктах, общей численностью 3824 души. Средний возраст составил - 26,92 года;

6. В 1-м населенном пункте были представлены помещичьи крестьяне, общей численностью 18 душ. Средний возраст составил - 24,9 года;

7. Также же существовал 1 населенный пункт, где были представлены беглые дворцовые крестьяне общей численностью 84 души. Средний возраст составил - 14,15 года;
8. Татары были представлены в 1-м населенном пункте, в количестве 197 душ. Средний возраст составил - 26,52 года;

9. Старые служивые солдаты численностью 14 душ, были представлены в 1-м населенном пункте. Средний возраст составил - 25,36 года;

10. Мастеровые люди числились в 1-м населенном пункте, общей численностью 13 душ. Средний возраст составил - 28,23 года.

В процессе рассмотрения данных было выяснено, что больше всего населения было среди дворцовых крестьян - 3824 души, затем с большим шли однодворцы 599 душ. Меньше всего числилось среди 3-х категорий: старые служивые солдаты - 14 душ, мастеровые люди 13 душ, разночинцы - 5 душ.

Самая большая продолжительность была среди 2-х категорий: мастеровые люди - 28,23 года и дворцовые крестьяне - 26,92 года. Самая маленькая продолжительность жизни была среди беглых дворцовых крестьян 14,15 года. 


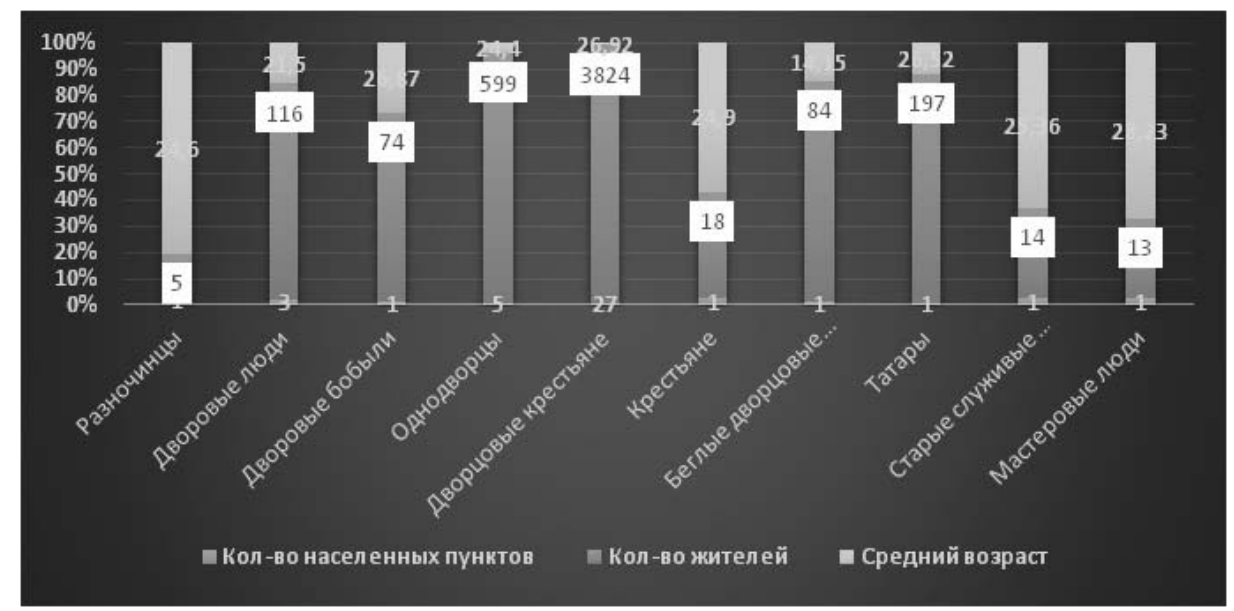

Гистограмма 2. Средний возраст по категориям крестьян в г. Красная слобода и Краснослободского уезда в 1745 г.

В заключение стоит отметить следующее:

1. В начале второй половины XVIII века на территории современной Республики Мордовия средняя продолжительность жизни составила - 26,24 года.

2. В большинстве случаев население данных мест относились к категории дворцовые крестьяне, но были и помещичьи крестьяне, дворовые люди, солдаты и однодворцы.

3. Самый большой средний возраст был среди 2-х категорий: мастеровые люди - 28,23 года и дворцовые крестьяне - 26,92 года. Самый маленький средний возраст был среди беглых дворцовых крестьян - 14,15 года.

4. В ходе проведения сравнительного анализа Московской и Воронежских губерниях выявляются существенные отличия, так как продолжительность жизни в Московской губернии была существенно выше.

В целом полученные данные показали, что на продолжительность жизни на территории Мордовского края во второй половине XVIII века оставалась на низком уровне. Также можно предположить, что положение мастеровых людей и дворцовых крестьян было намного лучше, чем у остального податного населения.

\section{ЛИТЕРАТУРА}

1. Российский государственный архив древних актов (РГАДА) - Ф-350. Книга переписная разночинцев, однодворцев, дворовых крестьян Воронежской губернии Шацкой провинции г. Красная слобода и Краснослободского у. 1745 г. Оп. 1, д. 1594.

2. Troitskaja Irina, Blum Alain. La mortalité en Russie aux XVIIle et XIXe siècles: estimations locales à partir des Revizii. In:Population, $51^{e}$ année, $n^{\circ} 2,1996$. pp. 303-328; 